\title{
Triclosan induces ROS-dependent cell death and autophagy in A375 melanoma cells
}

\author{
JING JIN ${ }^{1}$, NAIWEN CHEN ${ }^{1,2}$, HUAN PAN $^{3}$, WENHUA XIE $^{1}$, HONG XU $^{1,2}$, \\ SIYU LEI ${ }^{1,2}$, ZHIQIN GUO ${ }^{4}$, RENYE DING $^{5}$, YI HE $^{1}$ and JINLAI GAO ${ }^{6}$ \\ ${ }^{1}$ Department of Urology, The Affiliated Hospital of Jiaxing University, Jiaxing, Zhejiang 314001; \\ ${ }^{2}$ Department of Surgety, The Second Clinical Medical College of Zhejiang Chinese Medical University, Hangzhou, Zhejiang \\ 310053; Departments of ${ }^{3}$ Central Laboratory, ${ }^{4}$ Pathology and ${ }^{5}$ Clinical Laboratory, The Affiliated Hospital of Jiaxing \\ University; ${ }^{6}$ Department of Pharmacology, College of Medical, Jiaxing University, Jiaxing, Zhejiang 314001, P.R. China
}

Received October 15, 2019; Accepted June 23, 2020

DOI: 10.3892/ol.2020.11934

\begin{abstract}
Melanoma is a common type of cutaneous tumor, but current drug treatments do not satisfy clinical practice requirements. At present, mitochondrial uncoupling is an effective antitumor treatment. Triclosan, a common antimicrobial, also acts as a mitochondrial uncoupler. The aims of the present study were to investigate the effects of triclosan on melanoma cells and the underlying mechanisms. Mitochondrial membrane potential (MMP), mitochondrial morphology, mitochondrial reactive oxygen species (mito-ROS), intracellular superoxide anion and $\left[\mathrm{Ca}^{2+}\right]_{i}$ were measured using confocal microscopy. It was found that triclosan application was associated with decreased A375 cell viability in a dose- and time-dependent manner and these effects may have cell specificity. Furthermore, triclosan induced MMP depolarization, ATP content decrease, mito-ROS and $\left[\mathrm{Ca}^{2+}\right]_{\mathrm{i}}$ level increases, excessive mitochondrial fission, AMP-activated protein kinase (AMPK) activation and STAT3 inhibition. Moreover, these aforementioned effects were reversed by acetylcysteine treatment. Triclosan acute treatment also induced mitochondrial swelling, which was reversed after AMPK-knockdown associated with $\left[\mathrm{Ca}^{2+}\right]_{i}$ overload. Cell death was caused by STAT3 inhibition but not AMPK activation. Moreover, triclosan induced autophagy via the ROS/AMPK/p62/microtubule-associated protein 1A/1B-light chain 3 (LC3) signaling pathway, which may serve a role in feedback protection. Collectively, the present results suggested that triclosan increased mito-ROS
\end{abstract}

Correspondence to: Professor Yi He, Department of Urology, The Affiliated Hospital of Jiaxing University, 1882 Zhonghuan South Road, Jiaxing, Zhejiang 314001, P.R. China

E-mail: 84748480@qq.com

Dr Jinlai Gao, Department of Pharmacology, College of Medical, Jiaxing University, 1 Jiahang Road, Jiaxing, Zhejiang 314001, P.R. China E-mail: gaojinlai@zjxu.edu.cn

Key words: triclosan, apoptosis, autophagy, melanoma production in melanoma cells, following induced cell death via the STAT3/Bcl-2 pathway and autophagy via the AMPK/p62/LC3 pathway.

\section{Introduction}

Melanoma, originating in melanocytes and nevus cells, is one of the most common cutaneous neoplasms. Melanoma only represents a small subset of these tumors, yet it is the most common skin tumor type, with increasing incidence and mortality rates worldwide $(1,2)$. Currently, the primary treatments of malignant melanoma are surgical excision, immunotherapy, adjuvant chemotherapy, targeted therapy drugs (3) and radiotherapies $(2,4)$. However, these therapeutic strategies do not facilitate the current clinical practice requirements due to the high metastatic potential and drug resistance $(5,6)$. Moreover, long-term survival remains poor, even after treatment with these therapies (7). Therefore, it is important to develop novel drug candidates to overcome melanoma treatment limitations.

Previous studies have shown that mitochondrial uncoupling has become an effective antitumor treatment (8-10). Triclosan is a widely used antibacterial and antifungal agent in everyday personal care and consumer products, including toothpastes, antiseptic soaps and plastics, and is also a mild mitochondrial uncoupler (11-13). Therefore, triclosan may have anticancer effects in melanoma cells. Previous studies have focused on its antibacterial effects (14-16), thus few studies have investigated its anticancer properties and its effects in melanoma have not been shown.

Mitochondria are highly dynamic organelles that are involved in ATP generation, reactive oxygen species (ROS) generation and $\mathrm{Ca}^{2+}$ signaling, which continually undergo fusion and fission to maintain the balance between energy production and cell death under physiological condition (17). However, dysfunction of this balance has been recognized as an important factor for cancer progression. Mitochondrial bioenergetic and biosynthetic requirements are altered to resist cancer cell apoptosis, and promote tumor cell proliferation and migration, for example in glioblastoma and breast, lung and prostate cancer (18). In addition, ROS from mitochondria 
are considered novel signal mediators, which are involved in cell proliferation, tumor progression, differentiation and cell death (19). Thus, these properties of mitochondria contribute to this organelle becoming a promising target in cancer therapy.

The present study aimed to investigate the effect of triclosan on melanoma and the underlying mechanism. Thus, the present results may facilitate the development of triclosan as a potential treatment candidate against melanoma.

\section{Materials and methods}

Materials. Triclosan was obtained from Shanghai Baidi Biody-Bio Co., Ltd. Hoechst, Cal-AM, Eth-1, Fluo-3/AM, mito-Tracker, mito-SOX, tetramethylrhodamine methyl ester (TMRM) and DAPI were purchased from Thermo Fisher Scientific, Inc. Dihydroethidium dye was purchased from the Beyotime Institute of Biotechnology. Tempol, 3-MA and acetylcysteine (NAC) were purchased from Sigma Aldrich; Merck KGaA. Tempol $(0.5$ and $1 \mathrm{mM})$ is a radical scavenger that was used to test the effect of ROS levels on cytotoxicity induced by triclosan $(20 \mu \mathrm{M})$ in the lactate dehydrogenase $(\mathrm{LDH})$ release assay. S3I-201 was purchased from EMD Millipore. S3I-201 $(10$ and $20 \mu \mathrm{M})$ is a STAT3 inhibitor that was used to detect the effect of STAT3 activity change on cytotoxicity induced by triclosan $(20 \mu \mathrm{M})$ in the LDH release assay. Anti-p-STAT3 (Y705, \#9131, 1:1,000), anti-STAT3 (\#4904, 1:1,000), anti-p-AMPK (Thr172, \#2535, 1:1,000), anti-AMPK (\#2532, 1:1,000) and anti-p62 (\#88588, 1:1,000) were purchased from Cell Signaling Technology, Inc., Bcl-2 (ab196495, 1:1,000) antibody was purchased from Abcam and LC3 (L7543, 1:1,000) antibody was purchased from Sigma Aldrich; Merck KGaA.

Cell culture. A375 cells and HFF-1 cells were purchased from Zhongqiaoxinzhou Biotech. Cells were maintained in high glucose DMEM (HyClone; Cytiva) supplemented with $10 \%$ FBS (Biological Industries), $100 \mu \mathrm{g} / \mathrm{ml}^{-1}$ penicillin and $100 \mu \mathrm{g} / \mathrm{ml}^{-1}$ streptomycin at $37^{\circ} \mathrm{C}$ in $5 \% \mathrm{CO}_{2}$. The time of treatment and concentration are shown in the figure legends. Briefly, cells were treated with different concentrations $(0-200 \mu \mathrm{M})$ of drugs (triclosan, NAC, S3I-201, Tempol and 3-MA) for $24 \mathrm{~h}$ at $37^{\circ} \mathrm{C}$.

Measurement of cell viability. Cell viability was measured using a colorimetric MTT assay. A375 and HFF-1 cells were seeded into a 96 -well flat-bottomed plate at $5 \times 10^{3}$ per well and treated with or without triclosan at the indicated concentrations $(0-200 \mu \mathrm{M})$ for $24 \mathrm{~h}$ and then incubated with MTT $\left(5 \mathrm{mg} / \mathrm{ml}^{-1}\right)$ for $4 \mathrm{~h}$ at $37^{\circ} \mathrm{C}$. After $4 \mathrm{~h}$, the supernatant was removed and then the cells were incubated with $200 \mu \mathrm{l}$ DMSO for $3 \mathrm{~min}$ at room temperature to dissolve the purple formazan. The optical density (OD) was read at $490 \mathrm{~nm}$ using an Infinite M200 microplate reader (Tecan Trading AG).

$L D H$ release assay. $\mathrm{LDH}$ release in culture medium was evaluated by using LDH Cytotoxicity Assay kits (Beyotime Institute of Biotechnology) following the manufacturer's instructions. A375 cells were seeded $(5,000$ cells/well) in a 96-well plate and treated with triclosan (0-40 $\mu \mathrm{M})$, Tempol (0.5 and $1 \mathrm{mM})$, S3I-201 $(10$ and $20 \mu \mathrm{M})$, NAC $(1 \mu \mathrm{M})$ or combinations of these compounds for $24 \mathrm{~h}$. Subsequently, after cells were centrifuged at $444 \mathrm{x}$ g for $5 \mathrm{~min}$ at room temperature, the supernatant was collected and transferred into another 96-well plate for LDH assay test. The supernatant was incubated with LDH release testing buffer at room temperature for $30 \mathrm{~min}$. The OD was read at $490 \mathrm{~nm}$ by using an Infinite M200 microplate reader.

LIVE/DEAD cell staining. The live and dead cells were detected by using a LIVE/DEAD ${ }^{\circledR}$ cell viability assay kit (Invitrogen; Thermo Fisher Scientific, Inc.) according to the manufacturer's instructions. After A375 cells were seeded (50,000 cells/well) and adhered, they were treated with triclosan $(0-40 \mu \mathrm{M})$ for $24 \mathrm{~h}$ and then incubated with a mixture of $2 \mu \mathrm{M}$ calcein AM and $4 \mu \mathrm{M}$ EthD-1 for $15 \mathrm{~min}$ at $37^{\circ} \mathrm{C}$. The labeled cells were randomly visualized using a fluorescence microscope at $20 \mathrm{x}$ magnification and counted by using Image Pro Plus image analysis software (version 5.0; Media Cybernetics Inc.). The wavelength of fluorescence excitation was $488 \mathrm{~nm}$ for live cells and $594 \mathrm{~nm}$ for dead cells.

Measurement of mitochondrial membrane potential (MMP, $\Delta \Psi m)$. Cultured A375 cells were treated with TMRM $(50 \mathrm{nM})$ for $45 \mathrm{~min}$ and DAPI $\left(10 \mu \mathrm{g} / \mathrm{ml}^{-1}\right)$ for $15 \mathrm{~min}$ at $37^{\circ} \mathrm{C}$ and were then washed 4 times with warm PBS $\left(37^{\circ} \mathrm{C}\right)$. Fluorescence was then measured using a confocal microscope FLUOVIEW FV10i (magnification, x20). Confocal microscope images were captured using FV10-ASW version 3.1 Viewer software (Olympus Corporation). Images of TMRM fluorescence were obtained using an excitation at $630 \mathrm{~nm}$. Images of DAPI staining were obtained using an excitation at $460 \mathrm{~nm}$. The mitochondrial membrane potential was represented by the relative intensity of the fluorescence.

Measurement of ATP concentration. The concentration of ATP was measured using the luciferin-luciferase method following the protocol of the S0026 ATP detection assay kit (Beyotime Institute of Biotechnology). The A375 cells were collected on ice within $5 \mathrm{~min}$ and immediately lysed with $40 \mu 1$ lysis buffer from the ATP detection kit. After being centrifuged at $12,000 \mathrm{~g}$ at $4^{\circ} \mathrm{C}$ for $5 \mathrm{~min}$, the supernatant was transferred to a new $1.5 \mathrm{ml}$ tube for the ATP test. The luminescence from a 20- $\mu 1$ sample was assayed using an Infinite M200 microplate reader (luminometer mode) together with $100 \mu \mathrm{l}$ ATP detection buffer from the ATP assay kit. The samples' protein concentrations were measured using a BCA assay kit (P0010, Beyotime Institute of Biotechnology) at the same time and the ATP concentrations were normalized to the amount of total protein in each sample ( $\mu \mathrm{M} / \mathrm{mg}$, protein).

Staining of mitochondrial morphology. Cultured A375 cells were loaded with a mitochondrial selective probe mito-Tracker Green $(50 \mathrm{nM})$ at $37^{\circ} \mathrm{C}$ for $15 \mathrm{~min}$. Images were captured using confocal microscopy (magnification, x60). Images of mito-tracker Green fluorescence were obtained with an excitation at $490 \mathrm{~nm}$ and an emission at $516 \mathrm{~nm}$.

Measurement of mitochondrial reactive oxygen species (mito-ROS). Cultured A375 cells were loaded with Mito-SOX $(2 \mu \mathrm{M})$ for $20 \mathrm{~min}$ and DAPI at $37^{\circ} \mathrm{C}$ for $15 \mathrm{~min}$ and then 
the fluorescence was measured using confocal microscopy (magnification, x60). Images of Mito-SOX fluorescence were captured using an excitation at $630 \mathrm{~nm}$. Images of DAPI staining were captured by using an excitation at $460 \mathrm{~nm}$.

Measurement of intracellular superoxide anion concentration . Cultured A375 cells were loaded with dihydroethidium $(2 \mu \mathrm{M})$ at $37^{\circ} \mathrm{C}$ for $30 \mathrm{~min}$ and DAPI for $15 \mathrm{~min}$ and then the fluorescence was measured using a fluorescence microscope (magnification, x20). Images of dihydroethidium fluorescence were captured using an excitation at $594 \mathrm{~nm}$.

Western blotting. Protein samples from cultured A375 cells were harvested with RIPA lysis buffer (Beyotime Institute of Biotechnology) containing $1 \%$ protein inhibitor and $10 \%$ phosphatase inhibitor. After being centrifuged at $12,000 \mathrm{x} \mathrm{g}$ at $4^{\circ} \mathrm{C}$ for $15 \mathrm{~min}$, the supernatant was transferred and protein concentrations were assessed using a BCA assay kit (Bio-Rad Laboratories, Inc.). Equal amounts of protein (80 $\mu \mathrm{g} / \mathrm{lane})$ were loaded onto a $8-15 \%$ gel, resolved using SDS-PAGE and blotted onto a nitrocellulose membrane. After blocking with $5 \%$ non-fat milk at $4^{\circ} \mathrm{C}$ for $2 \mathrm{~h}$, the membranes were incubated with primary antibodies at $4^{\circ} \mathrm{C}$ overnight. The primary antibodies were anti-p-STAT3 (Y705, \#9131, 1:1,000), anti-STAT3 (\#4904, 1:1,000), anti-p-AMPK (Thr172, \#2535, 1:1,000), anti-AMPK (\#2532, 1:1,000), anti-p62 (\#88588, 1:1,000), anti-Bcl-2 (ab196495, 1:1,000) and anti-LC3 (L7543, 1:1,000). After being rinsed with TBS-0.1\% Tween 20 ( 5 min for 3 times), the membranes were subsequently incubated with fluorescence-conjugated goat anti-mouse IgG or goat anti-rabbit IgG secondary antibody (1:10,000;LI-COR Biosciences) for $1 \mathrm{~h}$ at room temperature. Images were captured using an Odyssey infrared imaging system and Odyssey version 3.0 software (LI-COR Biosciences).

siRNA transfection. A375 cells were seeded into 6-well flat-bottom plate at $5 \times 10^{3}$ per well. After cells adhered, the medium was replaced with serum-free DMEM and then the cells were transfected with small interfering (si)RNA AMPK $\alpha 1 / 2(80 \mathrm{nM})$ or scrambled siRNA used as a negative control (NC) (Shanghai GenePharma Co., Ltd.) using Lipofectamine ${ }^{\circledR} 2000$ (Invitrogen; Thermo Fisher Scientific, Inc.). After $6 \mathrm{~h}$ of incubation at $37^{\circ} \mathrm{C}$, the medium was removed and the cells were cultured for another $48 \mathrm{~h}$ before subsequent experiments. RNA oligo sequence were listed (5'-3') as follows: AMPK $\alpha 1$ forward, GCACGAGUUGACUGG ACAUTT and reverse, AUGUCCAGUCAACUCGUGCTT; AMPK $\alpha 2$ forward, GCUGACUUCGGACUCUCUATT and reverse, UAGAGAGUCCGAAGUCAGCTT; and NC forward, UUCUCCGAACGUGUCACGUTT and reverse, ACGUGA CACGUUCGGAGAATT.

Measurement of $\left[\mathrm{Ca}^{2+}\right]_{i}$. Cultured A375 cells were treated with Fluo-3/AM $(5 \mu \mathrm{M})$ and incubated at $37^{\circ} \mathrm{C}$ for $15 \mathrm{~min}$. Then the cells were incubated with DAPI for $15 \mathrm{~min}$ at $37^{\circ} \mathrm{C}$. The fluorescence intensity reflecting $\left[\mathrm{Ca}^{2+}\right]_{\mathrm{i}}$ was measured using confocal microscopy (magnification, x60). Images of Fluo-3/AM fluorescence were obtained with an excitation at $488 \mathrm{~nm}$ and an emission at $518 \mathrm{~nm}$, and measured using Image-Pro Plus version 5.0 (Media Cybernetics, Inc.).
Statistical analysis. Data were expressed by mean \pm standard error of the mean (SEM) (unless otherwise shown) and analyzed by using Sigma Plot version 12.5 (Systat Software, Inc.). Statistical significance of two groups was determined using an unpaired Student's t-test. For $>2$ groups, one-way ANOVA followed by Tukey's post hoc test was used. For the data with control value of 1 and no SEM, the randomized block ANOVA was used (20). $\mathrm{P}<0.05$ was considered to indicate a statistically significant difference.

\section{Results}

Triclosan induces cytotoxicity in A375 cells. The chemical structure of triclosan is shown in Fig. 1A. To evaluate the cytotoxicity of triclosan on melanoma cells, A375 cells were treated with various concentrations of Triclosan for $24 \mathrm{~h}$ and then cell viability was measured using a MTT and LDH release assays. In addition, cell death was detected using the LIVE/DEAD cell viability assay kit. It was demonstrated that triclosan inhibited A375 cell survival in a dose- and time-dependent manner (Fig. 1B-D). Fig. 1B demonstrated that $40 \mu \mathrm{M}$ triclosan could significantly induce a decrease in cell viability $(\mathrm{P}<0.01)$. In addition, the result of $\mathrm{LD}_{50}$ of triclosan is presented in Fig. S1, with the $\mathrm{LD}_{50}$ of triclosan in A375 cells being $52.72 \mu \mathrm{M}$. To further examine whether triclosan had beneficial selective effects between melanoma cells and other cell types, the same treatment was used on skin fibroblast HFF-1 cells. It was demonstrated that compared with HFF-1 cells, A375 cells were more sensitive to triclosan (Fig. 1E); triclosan significantly decreased A375 cell viability at 10 , 20, 40, 50, 80, 100 and $200 \mu \mathrm{M}$ (all $\mathrm{P}<0.01$ ). Therefore, the present results suggested that triclosan inhibited cell viability in a dose- and time-dependent manner in A375 cells and these effects have tumor cell selectivity.

Triclosan induces mitochondrial morphology and function changes in melanoma cells. Triclosan induces mitochondrial uncoupling in human mast cells and keratinocytes and has been reported to disrupt mitochondrial function $(13,21)$. Therefore, in order to investigate whether triclosan could induce mitochondrial uncoupling of melanoma cells, A375 cells were exposed to different concentrations of Triclosan for $24 \mathrm{~h}$ and MMP $(\Delta \Psi \mathrm{m})$ was measured using TMRM. It was revealed that compared with the control group, triclosan treatment depolarized MMP in dose-dependent manner (Fig. 2A). The present study also investigated whether triclosan-induced MMP could cause ATP depletion in A375 cells. It was demonstrated that ATP content was decreased after $20 \mu \mathrm{M}$ triclosan treatment (Fig. 2B). Collectively, the present results suggested that triclosan induced mitochondrial uncoupling in melanoma cells.

The mitochondria of A375 cells were stained using the mitochondria-specific probes mito-Tracker and mito-SOX. It was shown that acute triclosan treatment induced mitochondrial swelling and fission, accompanied by prominent ROS production within $10 \mathrm{~min}$ (Fig. 2C). The present study also examined the long-term effect of triclosan on mitochondrial morphology, showing that triclosan induced excessive mitochondrial fission and elevated production of ROS at 5-10 min, but mitochondrial swelling was not observed at $24 \mathrm{~h}$ 


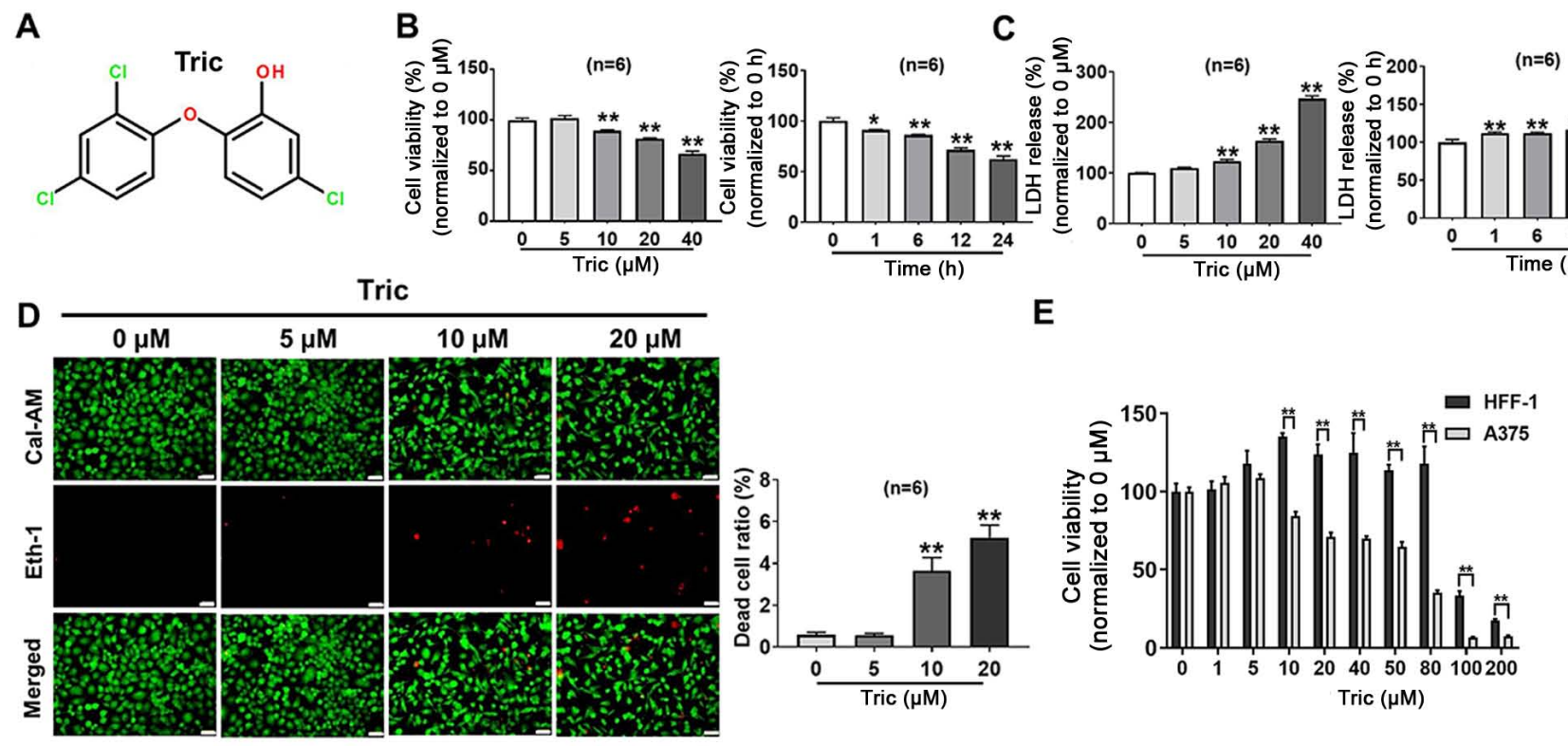

Figure 1. Triclosan induces cell death and decreases cell viability after $24 \mathrm{~h}$ treatment in A375 cells. (A) Chemical structure of triclosan. (B) Triclosan decreased viability of A375 cells after $24 \mathrm{~h}$ treatment in a dose-dependent manner, and $40 \mu \mathrm{M}$ triclosan decreased the viability of A375 cells in a time-dependent manner. (C) Triclosan increased LDH release in A375 cells after $24 \mathrm{~h}$ treatment in a dose-dependent manner, and $40 \mu \mathrm{M}$ triclosan increased LDH release in a time-dependent manner. (D) LIVE/DEAD cell viability assay results showed that triclosan induced A375 cell death after $24 \mathrm{~h}$ treatment in a dose-dependent manner. Scale bar, $50 \mu \mathrm{m}$. Statistical significance was determined using one-way ANOVA followed by Tukey's post hoc test. ${ }^{*} \mathrm{P}<0.05,{ }^{* *} \mathrm{P}<0.01 \mathrm{vs} .0 \mu \mathrm{M}$ or $0 \mathrm{~h}$. (E) Compared with HFF-1 cells, A375 cells were more sensitive to triclosan after $24 \mathrm{~h}$. Statistical significance was determined using an unpaired Student's t-test. ${ }^{* *} \mathrm{P}<0.01$ vs. HFF-1 cell. LDH, lactate dehydrogenase; Tric, Triclosan.

A
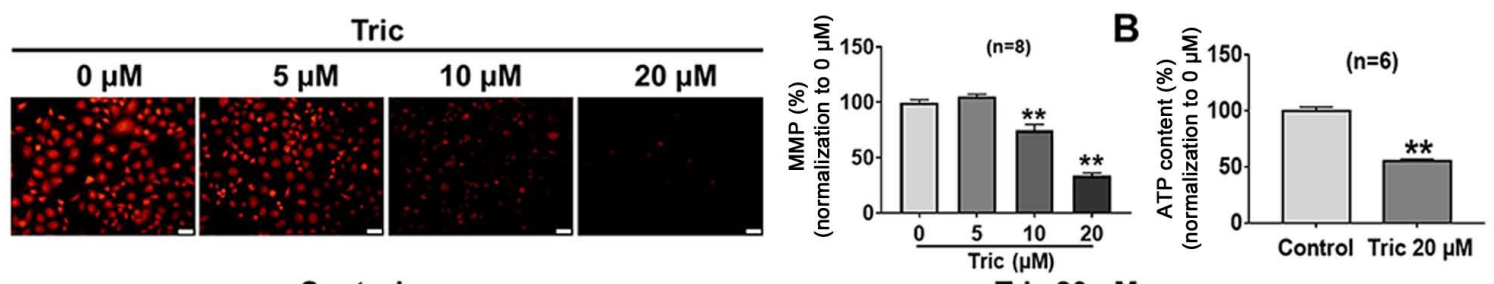

C
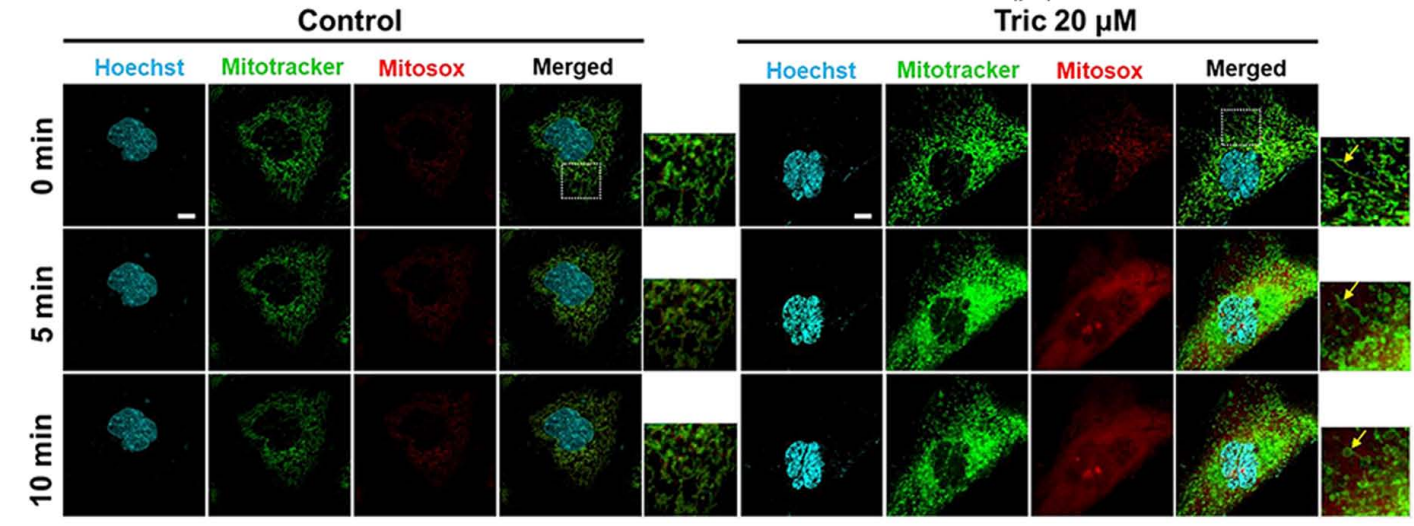

D

Control

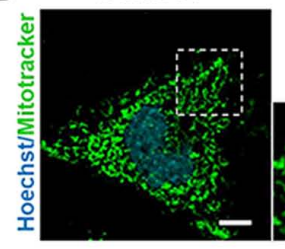

Tric $20 \mu \mathrm{M}$

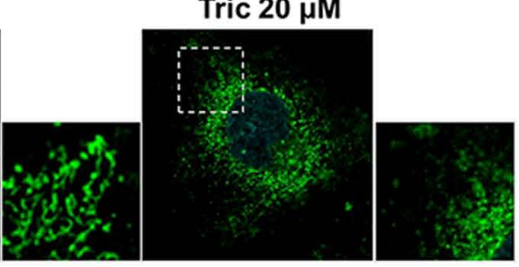

E

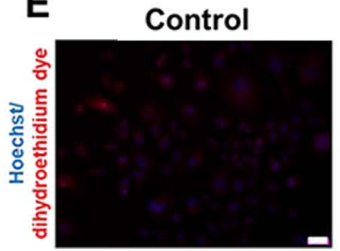

Tric $20 \mu \mathrm{M}$

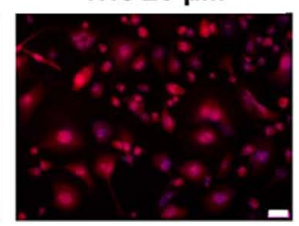

Figure 2. Triclosan induces mitochondrial morphology and function changes in A375 cells. (A) Triclosan dose-dependently decreased the MMP of A375 cells after $24 \mathrm{~h}$ treatment. Statistical significance was determined using one-way ANOVA followed by Tukey's post hoc test. Scale bar, $50 \mu \mathrm{m}$. (B) Analyzed data of ATP content indicated that $20 \mu \mathrm{M}$ triclosan decreased ATP in A375 cells after $24 \mathrm{~h}$. Statistical significance was determined using an unpaired Student's t-test. (C) Acute treatment of $20 \mu \mathrm{M}$ triclosan increased the mito-ROS levels, caused mitochondrial swelling and mitochondrial fission. Scale bar, $10 \mu \mathrm{m}$. (D) Enlarged images of the box area showed mitochondrial swelling and mitochondrial fission after $24 \mathrm{~h}$ treatment. Scale bar, $10 \mu \mathrm{m}$. (E) Triclosan ( $20 \mu \mathrm{M})$ increased the intracellular ROS levels after $24 \mathrm{~h}$ treatment. Scale bar, $50 \mu \mathrm{m} .{ }^{* *} \mathrm{P}<0.01$ vs. $0 \mu \mathrm{M}$ or control. mito-ROS, mitochondrial reactive oxygen species; MMP, mitochondrial membrane potential. 
(Fig. 2D and E). Mitochondrial swelling begins with changes in ion homeostasis of the matrix, which induces an osmotic imbalance between the cytosol and the matrix (22). As a result, increased colloidal osmotic pressure enhances the water influx leading to matrix swelling and mitochondrial size volume increased (22). Mitochondrial fission is shown as granular fragmentation (23). Therefore, the present results indicated that triclosan induced mitochondrial fission and ROS increase. Moreover, the acute effect of triclosan induced reversible mitochondrial swelling.

Triclosan activates AMPK and inhibits STAT3 activity in melanoma cells. As a mitochondrial uncoupler, triclosan decreases ATP content and induces AMP generation (13). AMPK is a downstream signaling protein of AMP and is subsequently activated (24). It has been previously reported that a cross-talk occurs between AMPK and STAT3 $(25,26)$, thus the present study investigated whether this cross-talk exists during triclosan-induced melanoma cell death. It was demonstrated that triclosan significantly increased p-AMPK protein expression at 10 and $20 \mu \mathrm{M}$, and decreased p-STAT3 protein expression at $20 \mu \mathrm{M}$ (both $\mathrm{P}<0.01$ ), so that the $\mathrm{p}$-AMPK/AMPK ratio increased and the p-STAT3/STAT3 ratio decreased, indicating that triclosan activated AMPK and inhibited STAT3 activity in melanoma cells after $24 \mathrm{~h}$ treatment (Fig. 3). Therefore, the present results suggested that triclosan may induce melanoma cell death and mitochondria dysfunction via AMPK activation and STAT3 activity inhibition.

ROS generation is involved in triclosan-induced cell death and mitochondrial dysfunction in A375 cells. ROS levels increase in tumor cells during proliferation and cell death (27-29). Triclosan elevated ROS production in A375 cells and the present study investigated whether triclosan-induced cell death resulted from a ROS increase. It was demonstrated that $20 \mu \mathrm{M}$ triclosan increased ROS production in melanoma cells, which was inhibited by the antioxidant NAC (Fig. 4A). Furthermore, triclosan-induced decrease in cell viability and increased LDH release was inhibited by co-treatment with NAC in A375 cells (Fig. 4B). The protective effects of NAC against triclosan-induced cell death were further demonstrated by the LIVE/DEAD cell viability assay (Fig. 4C), as $40 \mu \mathrm{M}$ triclosan induced significant cell death (showed by Eth-1), which was then reversed using $1 \mu \mathrm{M}$ NAC. Moreover, $20 \mu \mathrm{M}$ triclosan induced a marked mitochondrial fission, and NAC reversed triclosan-induced mitochondrial fission (Fig. 4D).

Oxidative stress is a trigger for AMPK activity and a repressor for STAT3 activity $(30,31)$. It was reported that triclosan activated AMPK activity, inhibited STAT3 activity (Fig. 3) and induced ROS levels (Fig. 4A and D), thus indicating that triclosan-induced ROS generation may contribute to triclosan-induced AMPK activation and STAT3 activity inhibition. Moreover, these triclosan-induced effects were reversed by NAC in A375 cells (Fig. 4E), thus suggesting that ROS are upstream molecules of the AMPK and STAT3 signaling pathways.

STAT3 activity inhibition is involved in triclosan-induced cell death in melanoma cells. STAT3 serves an important role in tumor cell survival $(32,33)$ and $\mathrm{Bcl}-2$ is a downstream signaling
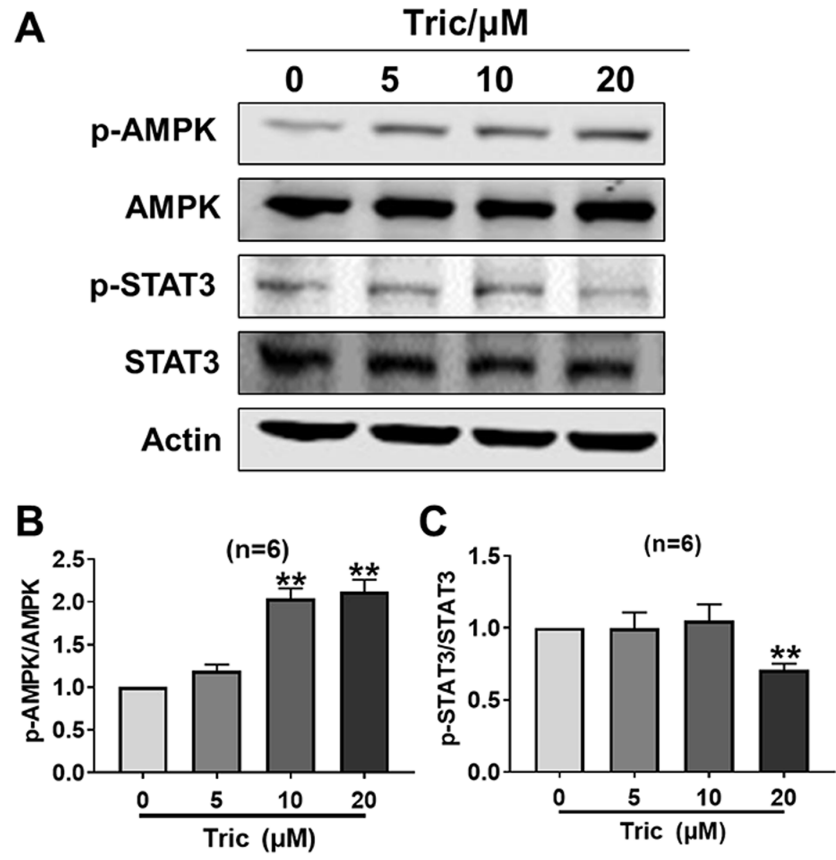

Figure 3. Triclosan activates AMPK and inhibits STAT3 activity. (A) Western blotting results indicated that triclosan dose-dependently increased the protein expression levels of $\mathrm{p}$-AMPK and decreased the protein expression levels of p-STAT3. (B) p-AMPK/AMPK ratio. (C) p-STAT3/STAT3 ratio. ${ }^{* *} \mathrm{P}<0.01$ vs. $0 \mu \mathrm{M}$. Statistical significance was determined using the randomized block ANOVA. p-, phosphorylated; AMPK, AMP-activated protein kinase; Tric, Triclosan.

molecule of STAT3 (34). Triclosan-induced STAT3 inhibition (Fig. 3) significantly inhibited Bcl-2 expression levels in A375 cells $(\mathrm{P}<0.05$; Fig. 5A). Furthermore, co-treatment with NAC reversed triclosan-induced $\mathrm{Bcl}-2$ downregulation. In addition, treatment with the STAT3 inhibitor S3I-201 increased triclosan-induced LDH release (Fig. 5B). Moreover, the ROS scavenger Tempol (35) also partially reversed triclosan-induced increase of LDH release (0.5 and $1 \mathrm{mM}$; Fig. 5B). Collectively, the present results suggested that triclosan led to cell death via the ROS/STAT3/Bcl-2 signaling pathway.

AMPK activation is not involved in Triclosan-induced cell death, but does affect $\left[\mathrm{Ca}^{2+}\right]_{i}$ transport in melanoma cells. To further investigate the effect of AMPK in triclosan-induced cell death, AMPK was knocked down in A375 cells using siRNA transfection. It was demonstrated that treatment with si-AMPK significantly decreased the protein expression levels of AMPK compared with the NC group $(\mathrm{P}<0.01$; Fig. 6A). In addition, in the si-AMPK+Triclosan+NAC group, knockdown of AMPK decreased the protective effect of NAC on triclosan-induced LDH release compared with in the NC+Triclosan+NAC group in A375 cells (Fig. 6C), while knockdown of AMPK did not significantly affect cell death and $\mathrm{LDH}$ release following triclosan treatment (Fig. 6B and C). Therefore, the present results indicated that AMPK activation was not involved in triclosan-induced cell death and AMPK inhibition may contribute to cell damage. It has been previously reported that AMPK activity regulates mitochondrial function $(36,37)$. Therefore, the present study hypothesized that triclosan may affect mitochondrial function in A375 cells by activating AMPK. It was demonstrated 
A

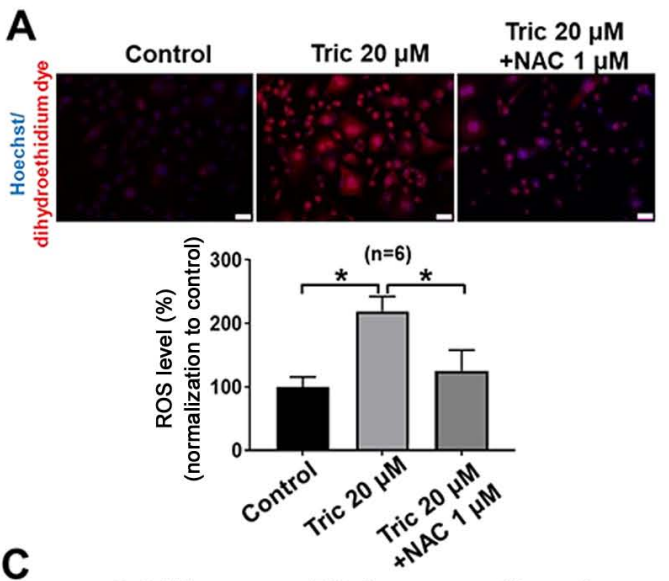

C

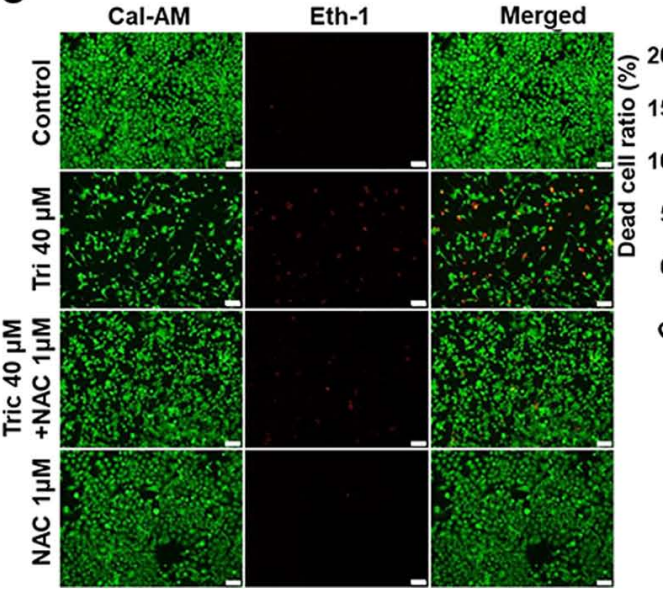

B

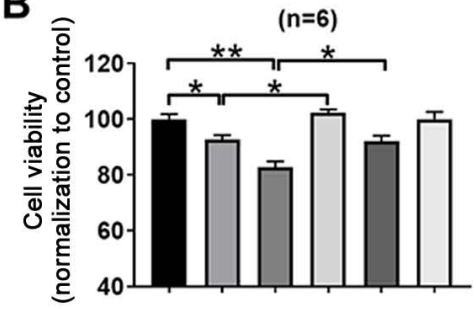

Control + - - - -

Tric $20 \mu \mathrm{M}-+-+-$

Tric $40 \mu \mathrm{M}--+-+$

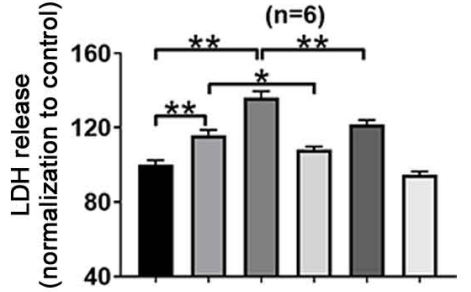

Control +---Tric $20 \mu \mathrm{M}-+-+-$ Tric $40 \mu \mathrm{M}--+-+$ NAC $1 \mu \mathrm{M}--+++$

Figure 4.NAC attenuates triclosan-induced cell death and mitochondrial damage and changes in AMPK and STAT3 activity. (A) NAC inhibited triclosan-induced excessive ROS production in A375 cells. Scale bar, $50 \mu \mathrm{m}$. (B and C) NAC reversed triclosan-induced cell death in A375 cells. Scale bar, $100 \mu \mathrm{m}$. (D) NAC reversed triclosan-induced excessive ROS production and mitochondrial damage in A375 cells. Scale bar, $10 \mu$ m. All statistical significance was determined using one-way ANOVA followed by Tukey's post hoc test. (E) NAC reversed triclosan-induced AMPK upregulation and STAT3 downregulation. ${ }^{*}<0.05$, ${ }^{* *} \mathrm{P}<0.01$. AMPK, AMP-activated protein kinase; NAC, acetylcysteine; ROS, reactive oxygen species.

A

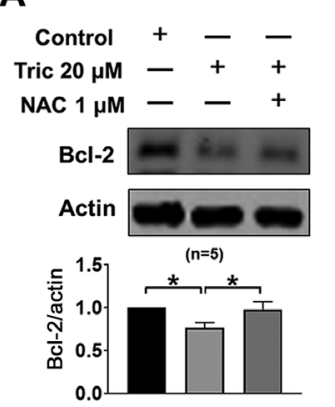

B

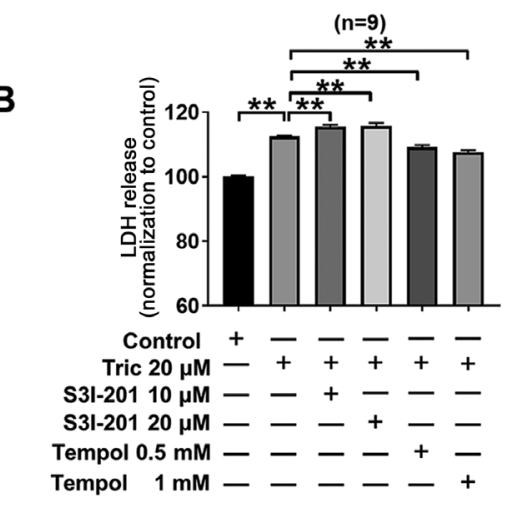

Figure 5. STAT3 activity inhibition promotes triclosan-induced cell death in A375 cells. (A) Triclosan $(20 \mu \mathrm{M})$ inhibited the protein expression levels of Bcl-2, which was attenuated by $1 \mu \mathrm{M}$ NAC. (B) Summary data showed that $20 \mu \mathrm{M}$ triclosan induced excessive $\mathrm{LDH}$ release, which was increased by S3I-201 and attenuated by Tempol. ${ }^{*} \mathrm{P}<0.05,{ }^{* * *} \mathrm{P}<0.01$. NAC, acetylcysteine; LDH, lactate dehydrogenase; Tric, Triclosan.

that triclosan induced mitochondrial swelling, but this effect was attenuated in AMPK-knockdown in A375 cells (Fig. 6D), indicating that AMPK could affect mitochondrial swelling. AMPK activation increases intracellular $\mathrm{Ca}^{2+}(38)$ and $\mathrm{Ca}^{2+}$-induced mitochondrial swelling and cytochrome $\mathrm{C}$

release in isolated mitochondria (39-41). The present results suggested that triclosan increased $\left[\mathrm{Ca}^{2+}\right]_{\mathrm{i}}$ (Fig. 6E) and this effect was decreased with si-AMPK or NAC treatment. Thus, AMPK-knockdown may inhibit $\mathrm{Ca}^{2+}$ transport, which could decrease $\mathrm{Ca}^{2+}$ release to the mitochondria and limit mitochondrial swelling.

Triclosan induces autophagy in A375 cells. Previous studies have revealed an association between AMPK and autophagy $(42,43)$ and that cell death is accompanied by autophagy $(44,45)$. As triclosan induced cell death and AMPK activation, the effects of triclosan on the levels of the marker protein of autophagy microtubule-associated protein 1A/1B-light chain 3 II (LC3-II) in A375 cells were examined. It was reported that triclosan increased LC3-II protein expression levels and this was reversed by NAC treatment (Fig. 7A). Furthermore, the autophagy inhibitor 3-MA increased triclosan-induced LDH release compared with triclosan alone (Fig. 7B), indicating that autophagy serves a protective role during triclosan-induced cell death. In order to identify the role of AMPK in triclosan-induced autophagy, the present study detected the expression levels of LC3 and p62 after AMPK-knockdown. It was found that the protein expression levels of AMPK were decreased after si-AMPK treatment, indicating that si-AMPK was successfully transfected into the A375 

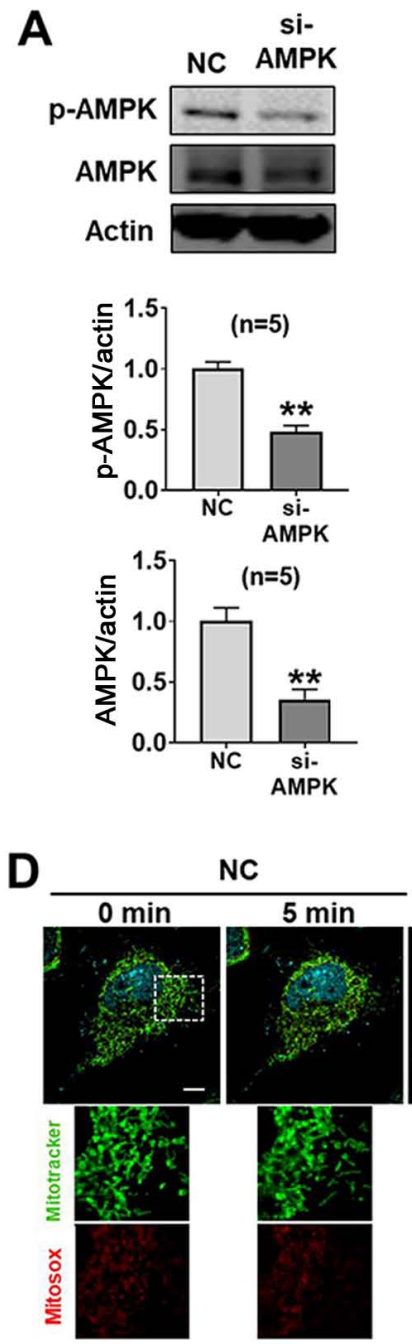
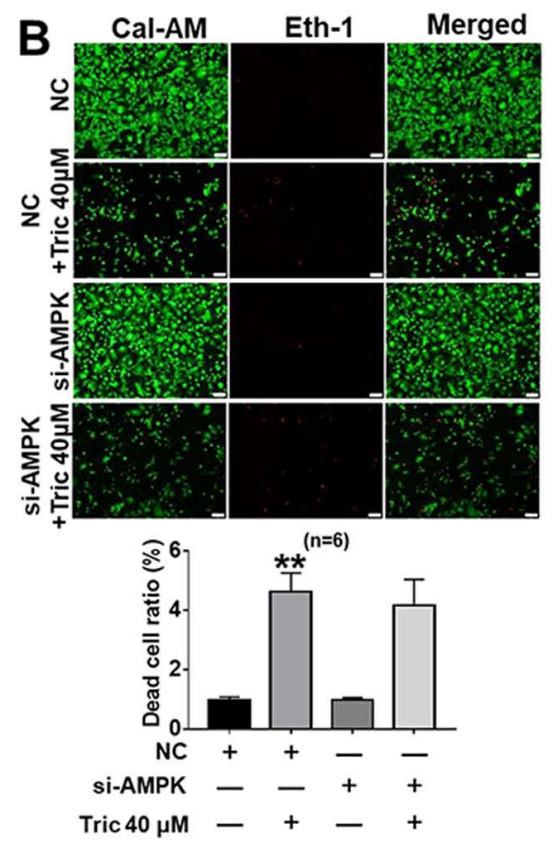

$\mathrm{NC}+$ Tric $20 \mu \mathrm{M}$
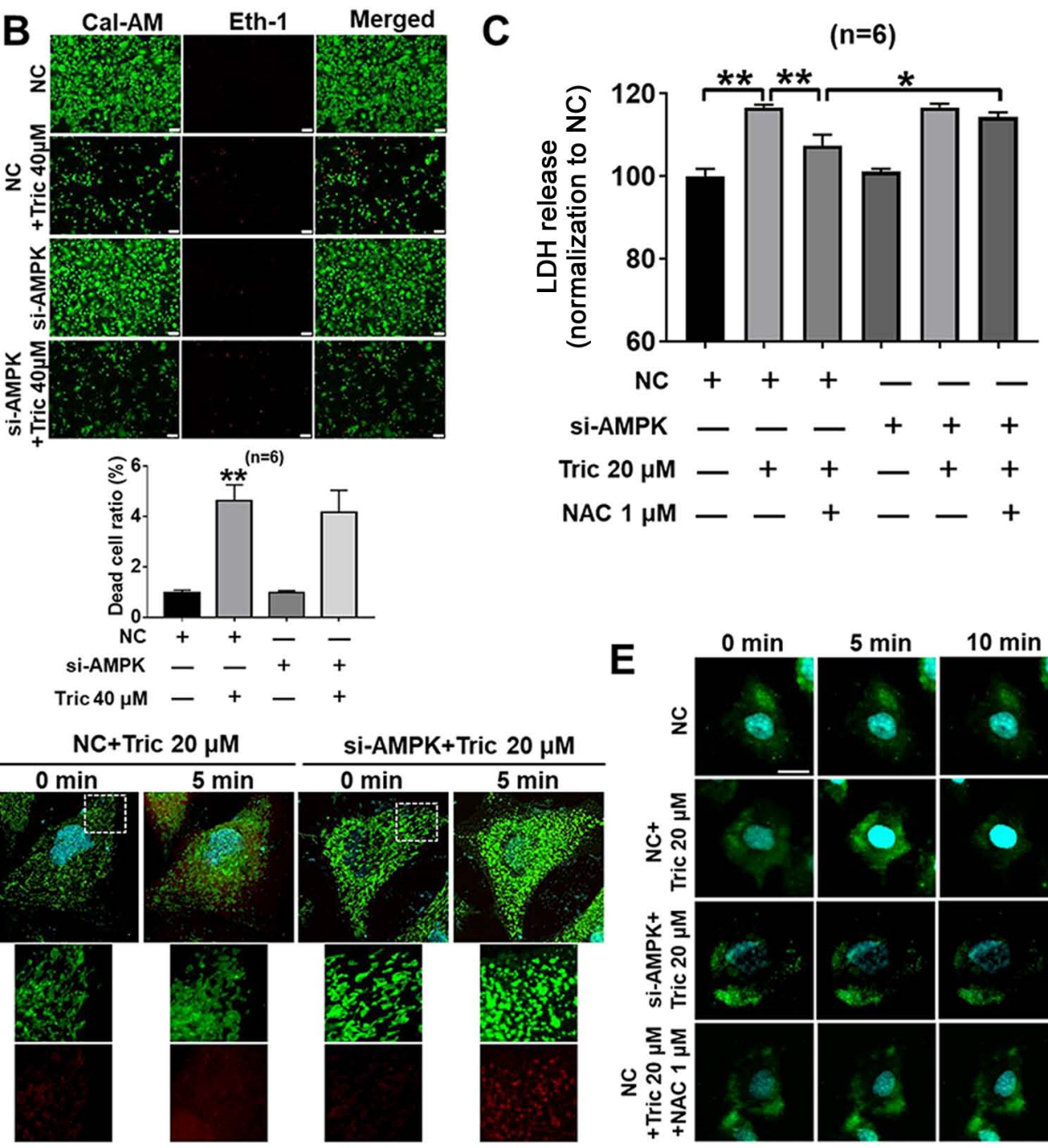

Figure 6. AMPK activation does not affect triclosan-induced cell death but induces mitochondrial dynamics by [Ca $\left.{ }^{2+}\right]_{\mathrm{i}}$ transport in $\mathrm{A} 375$ cells. (A) si-AMPK inhibited the protein expression levels of AMPK in A375 cells. Statistical significance of two groups was determined using unpaired Student's t-test. (B) Knockdown of AMPK had no significant effect on cell death. Scale bar, $50 \mu \mathrm{m}$. (C) NAC decreased the triclosan-induced increase of LDH release, but this effect was attenuated by knockdown of AMPK. (D) Triclosan induced mitochondrial swelling, but this effect was attenuated in knockdown of AMPK in A375 cells. Scale bar, $10 \mu \mathrm{m}$. (E) Triclosan increased $\left[\mathrm{Ca}^{2+}\right]_{\mathrm{I}}$, but this effect was decreased with si-AMPK treatment or NAC treatment. Scale bar, $10 \mu \mathrm{m}$. ${ }^{*} \mathrm{P}<0.05$, ${ }^{* * *} \mathrm{P}<0.01$. NC, negative control; NAC, acetylcysteine; AMPK, AMP-activated protein kinase; si, small interfering RNA.

cells (Fig. 7C). Moreover, triclosan did not increase the protein expression levels of LC3-II after si-AMPK treatment, and thus did not recruit p62 (Fig. 7C). Collectively, the present results indicated that AMPK may be involved in triclosan-induced autophagy. While si-AMPK treatment increased p-STAT3 expression levels in A375 cells, si-AMPK treatment did not prevent triclosan-induced inhibition of STAT3 (Fig. 7C) and cell death was observed (Fig. 6C). Thus, the present results suggested that STAT3 serves a role in triclosan-induced cell death. The mechanism of triclosan-induced cell death and autophagy was summarized in Fig. 8.

\section{Discussion}

Triclosan, a widely used antibacterial and antifungal agent, is present in everyday household personal care and consumer products $(11,12)$. Moreover, previous studies have focused on its antibacterial effect (14-16). To the best of our knowledge, the present study is the first to identify that triclosan induces cell death and autophagy in A375 cells. Furthermore, the present results suggested the importance of triclosan in cancer cell death as a novel antitumor drug. The present study primarily used the human melanoma cell line A375 to investigate underlying mechanism of action of triclosan.

Triclosan is a mild mitochondrial uncoupler (13). A previous study has demonstrated that triclosan induces mitochondrial depolarization in a dose-dependent manner in $\mathrm{HaCaT}$ cells, induces no significant mitochondrial swelling at $10 \mu \mathrm{M}$ and prevents mitochondrial swelling after subsequent $\mathrm{CaCl}_{2}$ treatment, which alone resulted in mitochondrial swelling (41). The present results indicated that triclosan induced significant mitochondrial swelling. Unlike the previous study that focused on healthy human skin cells (41), the present study used skin cancer cells. Hence, the present study hypothesized that triclosan may induce cell death by regulating mitochondrial function. Consistent with this hypothesis, it was demonstrated that triclosan decreased MMP and ATP content, induced reversible mitochondrial swelling and mitochondrial fission. 


\section{A}

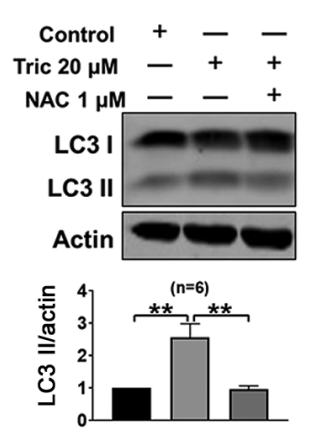

B

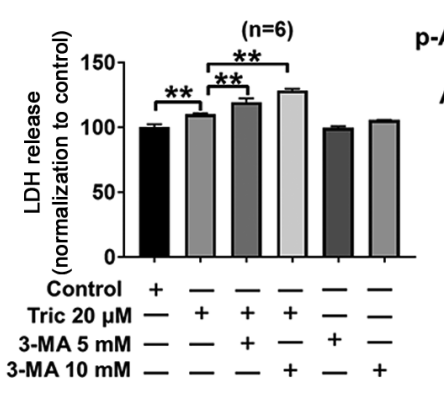

C
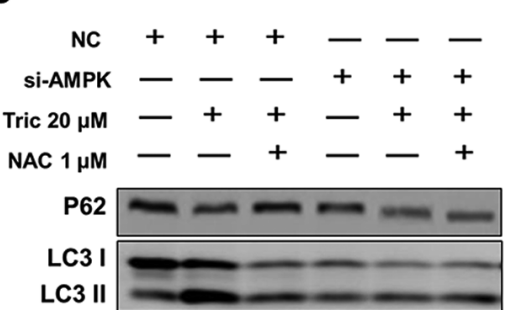

$\begin{aligned} \text { p-STAT3 } & \square-\cdots-\infty \\ \text { STAT3 } & -\infty-\infty-\infty\end{aligned}$

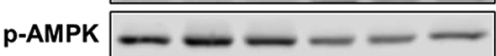

AMPK

Actin
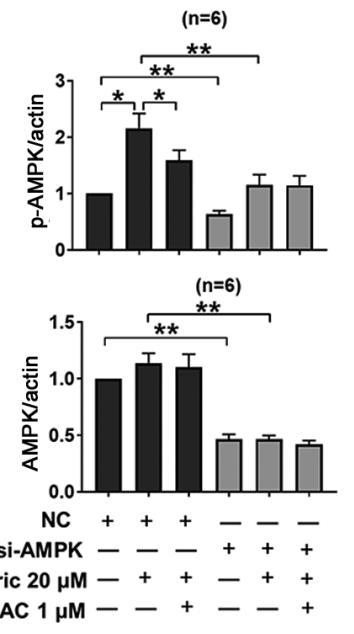

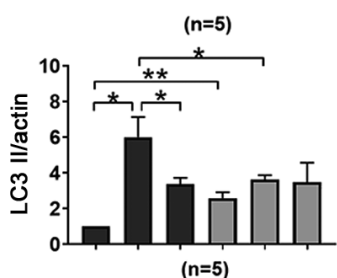

$(n=5)$
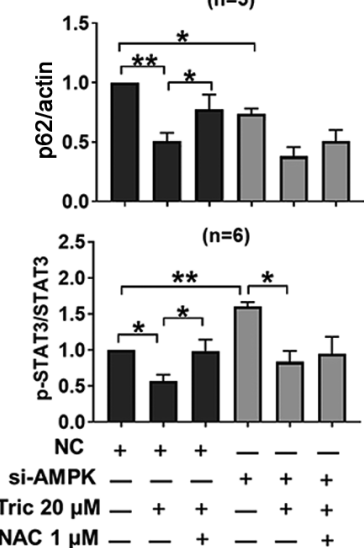

Figure 7. Triclosan induces AMPK-dependent autophagy in A375 cells. (A) NAC treatment attenuated the triclosan-induced autophagy response. (B) Triclosan-induced LDH release was increased by treatment with the autophagy inhibitor 3-MA. (C) Western blotting results indicated that triclosan inhibited p62 and p-STAT3 protein expression levels, and increased LC3II and p-AMPK expression levels, which were reversed by NAC. AMPK-knockdown increased STAT3 in A375 cells, but LC3II was decreased after triclosan treatment. ${ }^{*} \mathrm{P}<0.05,{ }^{* *} \mathrm{P}<0.01$. NC, negative control; NAC, acetylcysteine; AMPK, AMP-activated protein kinase; si, small interfering RNA; p-, phosphorylated; LC3II, microtubule-associated protein 1A/1B-light chain 3; LDH, lactate dehydrogenase.

\section{Triclosan}

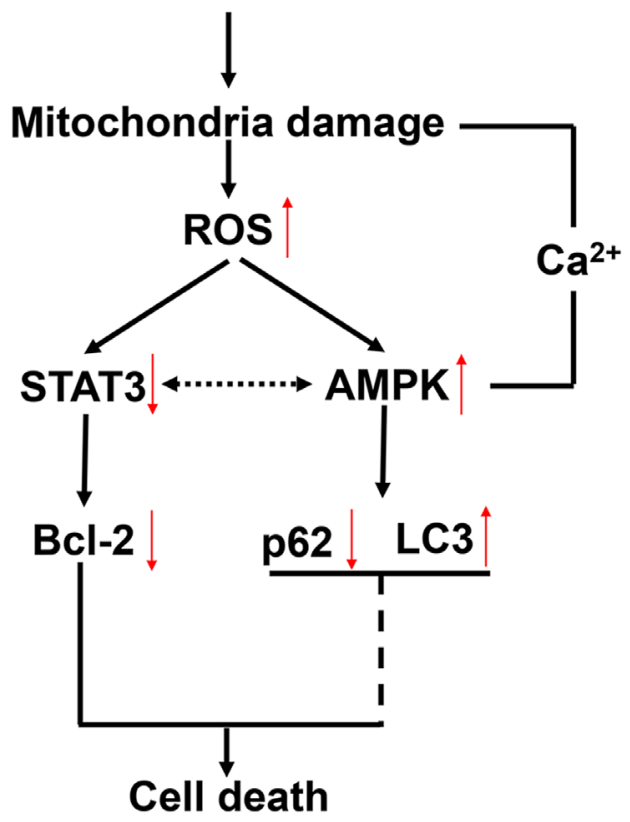

Figure 8. Mechanism of triclosan-induced cell death and autophagy. ROS, reactive oxygen species; AMPK, AMP-activated protein kinase; LC3, microtubule-associated protein 1A/1B-light chain 3 .

Mitochondria is a major source of ROS (46) and the present study investigated whether triclosan affected the production of ROS. It was demonstrated that triclosan increased the production of intracellular and mito-ROS.

Mito-ROS are physiological activators of AMPK (30). As a known target for treating type 2 diabetes and metabolic syndrome, AMPK has been regarded as a novel target for cancer prevention and treatment (47). The major mechanism activating AMPK is increasing the AMP/ATP ratio (48). The present results revealed that triclosan increased the AMP/ATP ratio. Furthermore, a previous study has shown that AMPK serves an important role in regulating mitochondrial function (30). Similarly, mitochondrial damage leads to ROS production, activating AMPK, and AMPK affects mitochondrial function in return (49).

AMPK promotes autophagy (43), which is the primary protective process in cells and also serves a role in cell death (50). The effect of autophagy on the anticancer action of AMPK is complicated; inducing or preventing autophagy both contribute to cancer therapy $(51,52)$. As triclosan induces cell death, the present study investigated the effects of triclosan on autophagic responses. It was demonstrated that triclosan increased autophagic responses, but the autophagy inhibitor 3-MA increased triclosan-induced LDH release, thus indicating that autophagy serves a protective role during triclosan-induced cell death. Furthermore, triclosan inhibited autophagy after si-AMPK transfection, which indicated that AMPK may be involved in triclosan-induced autophagy. Some studies have showed that AMPK activation suppresses the STAT3 signaling pathway $(26,53,54)$; however, genetic or pharmacological inhibition of STAT3 significantly increases the ADP/ATP ratio and activates AMPK signaling $(55,56)$. Therefore, there is a dual directional regulation mechanism between AMPK and STAT3. In the present study, while si-AMPK increased STAT3 expression levels, si-AMPK did not prevent the triclosan-induced decrease in STAT3 expression levels and cell death still occurred. Therefore, the present results suggested that STAT3 may serve an role in triclosan-induced cell death. 
A limitation of the present study is that comparative tests of triclosan and other anticancer drugs were not performed. Therefore, future studies should investigate this. However, the present study measured the effects of triclosan on the viability of normal cultured skin HFF-1 cells, indicating that the cytotoxic effects of triclosan are cancer-specific, which may contribute to its clinical application. Moreover, triclosan treatment, an ingredient of antiseptic soaps, may be applied to the skin. Thus, the ability to treat melanoma via application of therapeutic agents to the skin may be of clinical benefit.

\section{Acknowledgements}

Not applicable.

\section{Funding}

This project was supported by The Jiaxing Science and Technology Project (grant nos. 2017AY33004 and 2018AD32 083), the Medical Scientific Research Foundation of Zhejiang Province, China (grant nos. 2019KY694) and a Starting Research Fund from Jiaxin University (grant no. CD70519041).

\section{Availability of data and materials}

The datasets used and/or analyzed during the present study are available from the corresponding author on reasonable request.

\section{Authors' contributions}

JJ designed the project, performed the experiments, interpreted the data and wrote the paper. JG designed the project, interpreted the data and wrote the paper. NC, HP and WX performed the experiments and interpreted the data. HX, SL, ZG and RD performed the experiments. YH designed the project, revised the manuscript and gave final approval of the version to be published. All authors read and approved the final manuscript.

\section{Ethics approval and consent to participate}

Not applicable.

\section{Patient consent for publication}

Not applicable.

\section{Competing interests}

The authors declare that they have no competing interests.

\section{References}

1. Torre LA, Bray F, Siegel RL, Ferlay J, Lortet-Tieulent J and Jemal A: Global cancer statistics, 2012. CA Cancer J Clin 65: 87-108, 2015.

2. Miller KD, Siegel RL, Lin CC, Mariotto AB, Kramer JL, Rowland JH, Stein KD, Alteri R and Jemal A: Cancer treatment and survivorship statistics, 2016. CA Cancer J Clin 66: 271-289, 2016.

3. Abbas Q, Raza H, Hassan M, Phull AR, Kim SJ and Seo SY: Acetazolamide inhibits the level of tyrosinase and melanin: An enzyme kinetic, in vitro, in vivo, and in silico studies. Chem Biodivers 14: 2017.
4. Lee CW, Yen FL, Ko HH, Li SY, Chiang YC, Lee MH, Tsai MH and Hsu LF: Cudraflavone C induces apoptosis of A375.S2 melanoma cells through mitochondrial ROS production and MAPK activation. Int J Mol Sci 18: 1508, 2017.

5. Trunzer K, Pavlick AC, Schuchter L, Gonzalez R, McArthur GA, Hutson TE, Moschos SJ, Flaherty KT, Kim KB, Weber JS, et al: Pharmacodynamic effects and mechanisms of resistance to vemurafenib in patients with metastatic melanoma. J Clin Oncol 31: 1767-1774, 2013.

6. Tuong W, Cheng LS and Armstrong AW: Melanoma: Epidemiology, diagnosis, treatment, and outcomes. Dermatol Clin 30: 113-124, ix, 2012.

7. Eggermont AM, Spatz A and Robert C: Cutaneous melanoma. Lancet 383: 816-827, 2014.

8. Nowinski SM, Solmonson A, Rundhaug JE, Rho O, Cho J, Lago CU, Riley CL, Lee S, Kohno S, Dao CK, et al: Mitochondrial uncoupling links lipid catabolism to Akt inhibition and resistance to tumorigenesis. Nat Commun 6: 8137, 2015.

9. Samudio I, Fiegl M and Andreeff M: Mitochondrial uncoupling and the Warburg effect: Molecular basis for the reprogramming of cancer cell metabolism. Cancer Res 69: 2163-2166, 2009.

10. Baffy G, Derdak Z and Robson SC: Mitochondrial recoupling: A novel therapeutic strategy for cancer? Br J Cancer 105: 469-474, 2011.

11. Weatherly LM and Gosse JA: Triclosan exposure, transformation, and human health effects. J Toxicol Environ Health B Crit Rev 20: 447-469, 2017.

12. Ribado JV, Ley C, Haggerty TD, Tkachenko E, Bhatt AS and Parsonnet J: Household triclosan and triclocarban effects on the infant and maternal microbiome. EMBO Mol Med 9: 1732-1741, 2017.

13. Weatherly LM, Shim J, Hashmi HN, Kennedy RH, Hess ST and Gosse JA: Antimicrobial agent triclosan is a proton ionophore uncoupler of mitochondria in living rat and human mast cells and in primary human keratinocytes. J Appl Toxicol 36: 777-789, 2016.

14. Campbell L and Zirwas MJ: Triclosan. Dermatitis 17: 204-207, 2006.

15. Moretro T, Hoiby-Pettersen GS, Habimana O, Heir E and Langsrud S: Assessment of the antibacterial activity of a triclosan-containing cutting board. Int J Food Microbiol 146: 157-162, 2011.

16. Wu HX, Tan L, Tang ZW, Yang MY, Xiao JY, Liu CJ and Zhuo RX: Highly efficient antibacterial surface grafted with a triclosan-decorated poly(N-hydroxyethylacrylamide) brush. ACS Appl Mater Interfaces 7: 7008-7015, 2015.

17. Maycotte P, Marin-Hernandez A, Goyri-Aguirre M, Anaya-Ruiz M, Reyes-Leyva J and Cortes-Hernandez P: Mitochondrial dynamics and cancer. Tumour Biol 39: 1010428317698391, 2017.

18. Senft D and Ronai ZA: Regulators of mitochondrial dynamics in cancer. Curr Opin Cell Biol 39: 43-52, 2016.

19. Phull AR, Nasir B, Haq IU and Kim SJ: Oxidative stress, consequences and ROS mediated cellular signaling in rheumatoid arthritis. Chem Biol Interact 281: 121-136, 2018.

20. Lew M: Good statistical practice in pharmacology. Problem 2. Br J Pharmacol 152: 299-303, 2007.

21. Weatherly LM, Nelson AJ, Shim J, Riitano AM, Gerson ED, Hart AJ, de Juan-Sanz J, Ryan TA, Sher R, Hess ST and Gosse JA: Antimicrobial agent triclosan disrupts mitochondrial structure, revealed by super-resolution microscopy, and inhibits mast cell signaling via calcium modulation. Toxicol Appl Pharmacol 349: 39-54, 2018.

22. Park JY, Jang SY, Shin YK, Koh H, Suh DJ, Shinji T, Araki T and Park HT: Mitochondrial swelling and microtubule depolymerization are associated with energy depletion in axon degeneration. Neuroscience 238: 258-269, 2013.

23. Liu MY, Jin J, Li SL, Yan J, Zhen CL, Gao JL, Zhang YH, Zhang YQ, Shen X, Zhang LS, et al: Mitochondrial fission of smooth muscle cells is involved in artery constriction. Hypertension 68: 1245-1254, 2016.

24. Yan Y, Zhou XE, Xu HE and Melcher K: Structure and physiological regulation of AMPK. Int J Mol Sci 19: 3534, 2018.

25. Vasamsetti SB, Karnewar S, Kanugula AK, Thatipalli AR, Kumar JM and Kotamraju S: Metformin inhibits monocyte-to-macrophage differentiation via AMPK-mediated inhibition of STAT3 activation: Potential role in atherosclerosis. Diabetes 64: 2028-2041, 2015.

26. Wang M, Xin H, Tang W, Li Y, Zhang Z, Fan L, Miao L, Tan B, Wang $X$ and Zhu YZ: AMPK serves as a therapeutic target against anemia of inflammation. Antioxid Redox Signal 27: 251-268, 2017. 
27. Xu Z, Zhang F, Bai C, Yao C, Zhong H, Zou C and Chen X: Sophoridine induces apoptosis and $S$ phase arrest via ROS-dependent JNK and ERK activation in human pancreatic cancer cells. J Exp Clin Cancer Res 36: 124, 2017.

28. Chen W, Zou P, Zhao Z, Chen X, Fan X, Vinothkumar R, Cui R, Wu F, Zhang Q, Liang G and Ji J: Synergistic antitumor activity of rapamycin and EF24 via increasing ROS for the treatment of gastric cancer. Redox Biol 10: 78-89, 2016.

29. Chen X, Dai X, Zou P, Chen W, Rajamanickam V, Feng C, Zhuge W, Qiu C, Ye Q, Zhang X and Liang G: Curcuminoid EF24 enhances the anti-tumour activity of Akt inhibitor MK-2206 through ROS-mediated endoplasmic reticulum stress and mitochondrial dysfunction in gastric cancer. Br J Pharmacol 174 1131-1146, 2017

30. Rabinovitch RC, Samborska B, Faubert B, Ma EH, Gravel SP Andrzejewski S, Raissi TC, Pause A, St-Pierre J and Jones RG: AMPK maintains cellular metabolic homeostasis through regulation of mitochondrial reactive oxygen species. Cell Rep 21: 1-9, 2017.

31. Chen W, Li P, Liu Y, Yang Y, Ye X, Zhang F and Huang H: Isoalantolactone induces apoptosis through ROS-mediated ER stress and inhibition of STAT3 in prostate cancer cells. J Exp Clin Cancer Res 37: 309, 2018.

32. Kryczek I, Lin Y, Nagarsheth N, Peng D, Zhao L, Zhao E, Vatan L, Szeliga W, Dou Y, Owens S, et al: IL-22(+)CD4(+) T cells promote colorectal cancer stemness via STAT3 transcription factor activation and induction of the methyltransferase DOT1L. Immunity 40: 772-784, 2014

33. Chai EZ, Shanmugam MK, Arfuso F, Dharmarajan A, Wang C, Kumar AP, Samy RP, Lim LH, Wang L, Goh BC, et al: Targeting transcription factor STAT3 for cancer prevention and therapy. Pharmacol Ther 162: 86-97, 2016.

34. Min K, Lawan A and Bennett AM: Loss of MKP-5 promotes myofiber survival by activating STAT3/Bcl-2 signaling during regenerative myogenesis. Skelet Muscle 7: 21, 2017.

35. Ye S, Xu P, Huang M, Chen X, Zeng S, Wang Q, Chen J, Li K, Gao W, Liu R, et al: The heterocyclic compound Tempol inhibits the growth of cancer cells by interfering with glutamine metabolism. Cell Death Dis 11: 312, 2020.

36. Lantier L, Fentz J, Mounier R, Leclerc J, Treebak JT, Pehmoller C, Sanz N, Sakakibara I, Saint-Amand E, Rimbaud S, et al: AMPK controls exercise endurance, mitochondrial oxidative capacity, and skeletal muscle integrity. FASEB J 28: 3211-3224, 2014

37. Toyama EQ, Herzig S, Courchet J, Lewis TL Jr, Loson OC, Hellberg K, Young NP, Chen H, Polleux F, Chan DC and Shaw RJ: Metabolism. AMP-activated protein kinase mediates mitochondrial fission in response to energy stress. Science 351: 275-281, 2016

38. Vlachaki Walker JM, Robb JL, Cruz AM, Malhi A, Weightman Potter PG, Ashford MLJ, McCrimmon RJ, Ellacott KLJ and Beall C: AMP-activated protein kinase (AMPK) activator A-769662 increases intracellular calcium and ATP release from astrocytes in an AMPK-independent manner. Diabetes Obes Metab 19: 997-1005, 2017.

39. Javadov S, Chapa-Dubocq X and Makarov V: Different approaches to modeling analysis of mitochondrial swelling. Mitochondrion 38: 58-70, 2018.

40. Abe T, Takagi N, Nakano M, Tanonaka K and Takeo S: The effects of monobromobimane on calcium and phenylarsineoxide-induced mitochondrial swelling and cytochrome $\mathrm{C}$ release in isolated brain mitochondria. Biol Pharm Bull 27: 524-527, 2004.

41. Teplova VV, Belosludtsev KN and Kruglov AG: Mechanism of triclosan toxicity: Mitochondrial dysfunction including complex II inhibition, superoxide release and uncoupling of oxidative phosphorylation. Toxicol Lett 275: 108-117, 2017.
42. Dite TA, Ling NXY, Scott JW, Hoque A, Galic S, Parker BL, Ngoei KRW, Langendorf CG, O'Brien MT, Kundu M, et al: The autophagy initiator ULK1 sensitizes AMPK to allosteric drugs. Nat Commun 8: 571, 2017.

43. Bujak AL, Crane JD, Lally JS, Ford RJ, Kang SJ, Rebalka IA, Green AE, Kemp BE, Hawke TJ, Schertzer JD and Steinberg GR: AMPK activation of muscle autophagy prevents fasting-induced hypoglycemia and myopathy during aging. Cell Metab 21: 883-890, 2015

44. Sun L, Hu L, Cogdell D, Lu L, Gao C, Tian W, Zhang Z, Kang Y, Fleming JB and Zhang W: MIR506 induces autophagy-related cell death in pancreatic cancer cells by targeting the STAT3 pathway. Autophagy 13: 703-714, 2017.

45. Sutton MN, Yang H, Huang GY, Fu C, Pontikos M, Wang Y, Mao W, Pang L, Yang M, Liu J, et al: RAS-related GTPases DIRAS1 and DIRAS2 induce autophagic cancer cell death and are required for autophagy in murine ovarian cancer cells. Autophagy 14: 637-653, 2018.

46. Bolisetty S and Jaimes EA: Mitochondria and reactive oxygen species: Physiology and pathophysiology. Int J Mol Sci 14: 6306-6344, 2013.

47. Luo $\mathrm{Z}$, Zang $\mathrm{M}$ and Guo $\mathrm{W}$ : AMPK as a metabolic tumor suppressor: Control of metabolism and cell growth. Future Oncol 6: 457-470, 2010.

48. Ke R, Xu Q, Li C, Luo L and Huang D: Mechanisms of AMPK in the maintenance of ATP balance during energy metabolism. Cell Biol Int 42: 384-392, 2018.

49. Yang YF, Wang YY, Hsiao M, Lo S, Chang YC, Jan YH, Lai TC, Lee YC, Hsieh YC and Yuan SF: IMPAD1 functions as mitochondrial electron transport inhibitor that prevents ROS production and promotes lung cancer metastasis through the AMPK-Notch1-HEY1 pathway. Cancer Lett 485: 27-37, 2020.

50. Mizushima N, Levine B, Cuervo AM and Klionsky DJ: Autophagy fights disease through cellular self-digestion. Nature 451: 1069-1075, 2008.

51. Lu L, Shen X, Tao B, Lin C, Li K, Luo Z and Cai K: The nanoparticle-facilitated autophagy inhibition of cancer stem cells for improved chemotherapeutic effects on glioblastomas. J Mater Chem B 7: 2054-2062, 2019.

52. Wang RX, Xu XE, Huang L, Chen S and Shao ZM: eEF2 kinase mediated autophagy as a potential therapeutic target for paclitaxel-resistant triple-negative breast cancer. Ann Transl Med 7: 783, 2019.

53. Ge A, Wang S, Miao B and Yan M: Effects of metformin on the expression of AMPK and STAT3 in the spinal dorsal horn of rats with neuropathic pain. Mol Med Rep 17: 5229-5237, 2018.

54. Li H, Lee J, He C, Zou MH and Xie Z: Suppression of the mTORC1/STAT3/Notch1 pathway by activated AMPK prevents hepatic insulin resistance induced by excess amino acids. Am J Physiol Endocrinol Metab 306: E197-E209, 2014

55. Gao JL, Zhao J, Zhu HB, Peng X, Zhu JX, Ma MH, Fu Y, Hu N, Tai Y, Xuan XC and Dong DL: Characterizations of mitochondrial uncoupling induced by chemical mitochondrial uncouplers in cardiomyocytes. Free Radic Biol Med 124: 288-298, 2018.

56. Zhang W, Xia D, Li Z, Zhou T, Chen T, Wu Z, Zhou W, Li Z, $\mathrm{Li} \mathrm{L}$ and $\mathrm{Xu} \mathrm{J}$ : Aurora-A/ERK1/2/mTOR axis promotes tumor progression in triple-negative breast cancer and dual-targeting Aurora-A/mTOR shows synthetic lethality. Cell Death Dis 10: 606, 2019.

This work is licensed under a Creative Commons Attribution-NonCommercial-NoDerivatives 4.0 International (CC BY-NC-ND 4.0) License. 